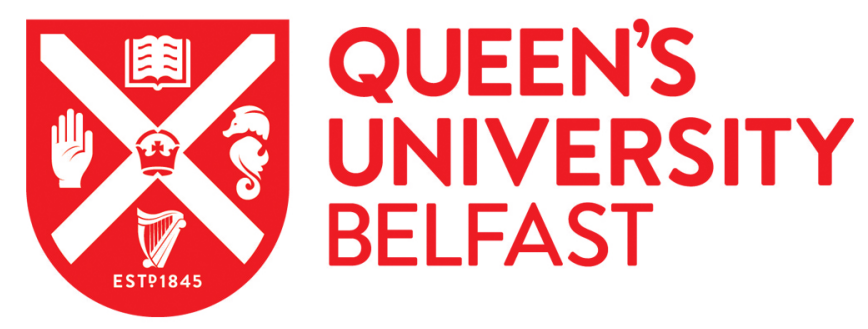

\title{
Mapping the managerial areas of Building Information Modeling (BIM) using scientometric analysis
}

He, Q., Wang, G., Luo, L., Shi, Q., Xie, J., \& Meng, X. (2017). Mapping the managerial areas of Building Information Modeling (BIM) using scientometric analysis. International Journal of Project Management, 35(4), 670-685. https://doi.org/10.1016/j.jproman.2016.08.001

Published in:

International Journal of Project Management

Document Version:

Peer reviewed version

Queen's University Belfast - Research Portal:

Link to publication record in Queen's University Belfast Research Portal

Publisher rights

( 2016 Elsevier Ltd, APM and IPMA. All rights reserved.. This manuscript version is made available under the CC-BY-NC-ND 4.0 license http://creativecommons.org/licenses/by-nc-nd/4.0/ which permits distribution and reproduction for non-commercial purposes, provided the author and source are cited.

\section{General rights}

Copyright for the publications made accessible via the Queen's University Belfast Research Portal is retained by the author(s) and / or other copyright owners and it is a condition of accessing these publications that users recognise and abide by the legal requirements associated with these rights.

Take down policy

The Research Portal is Queen's institutional repository that provides access to Queen's research output. Every effort has been made to ensure that content in the Research Portal does not infringe any person's rights, or applicable UK laws. If you discover content in the Research Portal that you believe breaches copyright or violates any law, please contact openaccess@qub.ac.uk. 


\section{Mapping the managerial areas of Building Information Modeling (BIM) using}

scientometric analysis

Abstract: The successful adoption of Building Information Modeling (BIM) leads to the subsequent need for improving management practices and stakeholders' relationships. Previous studies have attempted to explore solutions for non-technical issues; however, a systematic and quantitative review of the details of non-technical field, namely, the managerial areas of BIM (MA-BIM), seems to be missing. Hence, a scientometric approach is used to construct knowledge maps in MA-BIM, thereby allowing bibliometric data to provide an objective and accurate perspective in the field as a whole. Through keyword and abstract term analysis of 126 related papers published from 2007 to 2015, an integrated conceptual framework is proposed to summarize current status and structure future directions of MA-BIM based on five principal research areas. This study shows the transformation of MA-BIM from an individual approach to a wide-ranging organizational strategy. It provides new insights into managing BIM projects by referring to the accurate representation and analysis of previous research efforts.

Keywords: Construction project management; Building Information Modeling (BIM);

\section{Scientometrics; Literature analysis}

\section{Introduction}

Construction projects, particularly megaprojects, are becoming significantly complex and difficult to manage (Bryde et al., 2013). To cope with the increasing complexity and difficulty of project management, BIM has been developing at a rapid pace and becoming extensively utilized. The benefits of BIM in different types of construction projects are manifold and generally recognized by involved stakeholders (Eastman et al., 2011; Gu and London, 2010). 
Despite its immense technical advantages and value potential, the facts remain that the use of BIM worldwide still falls considerably short of its capabilities; many construction projects even disregard BIM (Cao et al., 2014). Barlish and Sullivan (2012) determined that returns on investment (ROI) generated by BIM may vary considerably from project to project. Oakley (2012) revealed minimal effects of several construction projects with the use of BIM on project performance. Although the technology side of BIM is considerably maturing in the construction industry, the managerial areas of BIM (MA-BIM) still have limitations.

For a construction project, BIM is not merely a software suite. However, obtaining the promised project benefits of BIM seems to hinge on management changes instead of technology issues. A recent example is the Shanghai Tower, in which the critical challenge of BIM implementation was not the technical aspects but the coordination among 8 BIM teams with members having diverse occupational backgrounds and different interest orientations. Among the involved parties, the Shanghai Construction Group was the general contractor and one of the owners with a $4 \%$ of the share on the project (Shanghai Tower, 2015). The IPD-ish partnership (El Asmar et al., 2013) significantly facilitated the involvement of Shanghai Tower contractor in the preplanning and design stages. In this regard, the non-technical challenge necessitates an industry-wide demand for the studies on the MA-BIM. Volk et al. (2014) presented a comprehensive review on BIM from a "broad" sense, which comprises functional, informational, technical and organizational/legal issues throughout the entire lifecycle of a project. According to Volk et al. (2014), the organizational/legal issues are what MA-BIM needs to improve for project performance. For these reasons, MA-BIM could be proposed as: 
Organizational and legal strategies for coordinating and managing overall project information, processes and aligning project policies to improve the level of BIM adoption and implementation.

Literature review is regarded as an expedient approach to gain in-depth understanding of a research area. Through a systematic examination of existing studies, state-of-the-art advancements and emergent trends can be identified with the purpose of spurring encouragement for future studies. Despite the importance of critical review, almost no such work has yet been conducted regarding MA-BIM. Therefore, the current study undertakes a scientometric analysis of MA-BIM articles published from 2007 to 2015. Different from previous studies, this study does not distinguish between sources specific to MA-BIM, which enables data to provide a highly accurate general perspective in the field.

The objectives of this study are as follows: (1) to summarize MA-BIM studies from 2007 to 2015 ; (2) to acquire a holistic research status for MA-BIM from the perspective of keyword co-occurrence network, as well as to identify research theme-divisions through abstract term cluster analysis; (3) to identify emergent trends from studies in this field through keyword burst detection; and (4) to develop an MA-BIM framework that illustrates a future research roadmap. The rest of this paper is structured as follows. Section 2 elaborates on the research method used in this study. Section 3 presents the results of the keyword co-occurrence analysis and burst detection, followed by Section 4 that describes the results and findings from the abstract term cluster analysis. Then Section 5 develops and presents the MA-BIM conceptual framework based on the scientometric analysis. Finally, Section 6 concludes the findings of this study. 


\section{Research method}

\subsection{Paper retrieval}

To achieve the research objectives of this study, academic journals with the BIM publications were identified. The list of publications was obtained using two databases, namely, Scopus and Web of Science (WoS), for a comprehensive search on the subject area. WoS database covers over 12,000 of high impact journals worldwide, including open access journals and over 150,000 conference proceedings (Thompson-Reuters, 2014). And Scopus includes over 21,500 peer-reviewed journals, 7.2 million conference papers, and over 60 million records (Elsevier, 2016). The integration of sources from these two databases was considered sufficient to justify broad conclusions regarding the overall development of BIM.

Given the difficulty of searching each related article, a delimitation of the research boundary is frequently necessary (Chen et al., 2015). The main point of each paper should be determined by its research objectives, methodologies, and major contributions. In the current study, three criteria were proposed during the delimitation process of the BIM literature in the managerial areas. Fig. 1 shows the research framework of this study.

Insert Fig. 1

Firstly, only papers in peer-reviewed English journals were included for the review with considering their impact positions in the BIM research in terms of SCImago Journal Rank and H-index. Book reviews, editorials, and conference papers were excluded so that all retrieved papers could be screened using an identical analytical construct in terms of research aims and methods (Mok et al., 2015).

Secondly, the topics of these papers were limited to the managerial issues in BIM adoption and implementation rather than the technical development of BIM. The topic of each paper 
was determined by its research aims and methods from abstract. Those papers, which aim at providing technical solutions of BIM without referring to project strategies for improved BIM adoption level or implementation process, were preliminarily excluded. Meanwhile, the topic of each paper could also be identified from the research methods. It is noteworthy that interviews and questionnaires are typically used as the principal means of investigating the managerial issues of BIM. In contrast, technologies integration and systems development are essentially employed to address the technical issues of BIM.

Thirdly, papers aimed at addressing functional issues that describe BIM functionalities and applications, informational issues that describe industry foundation classes (IFC) and model view definition (MVD), and technical issues that describe data capture, data processing, object recognition, and modeling, were excluded. After identifying the research aims and methods from abstracts, there was still a need for in-depth understanding of the primary contents of each paper. For example, if the main body of a paper discussed the whole process of BIM plug-in development, but nearly had no relationship with organizational/legal issues, it was screened out. To decrease potential bias during the selection of target papers, the contents of each paper were screened by different authors to identify the ones suitable for this study.

The search rule in this study was ("BIM" OR "building information modeling" OR "building information modelling" OR "building information model" OR "virtual design and construction" OR "VDC" OR "as-built model” OR "virtual model”) AND ("management" OR "managerial" OR "managing" OR "manage"). To avoid omissions of target papers, the timespan of the publication search was set for "all years" (ended in August 18, 2015). 
According to the first criterion, a total of 308 journal papers were retrieved. As shown in Table 1, 16 journals are selected in this process. These journals have published at least one paper that fit the first criterion, and are highly ranked by construction management researchers. Despite the rigorous search rule, some retrieved publications appear to be less relevant. Based on the second and third criteria, 126 papers were identified for further analysis after the filtering process. The first study on the 'selection of papers' list is Fox and Hietanen (2007), which conducted an investigation on the potential of BIM for interorganizational use in Finland, including its automational, informational, and transformational effects. The subsequent analyzing process is thus set from 2007 to 2015 in CiteSpace.

Insert Table 1 about here

\subsection{Scientometric analysis}

Due to a wide spectrum of research topics in relation to MA-BIM, there is little prospect of characterizing the overall field through manual literature analysis. And the manual review, while insightful, is prone to be biased and limited in terms of subjective interpretation.

Therefore, the current study provides a holistic analysis of MA-BIM using the scientometric technique, a research method that refers to knowledge domain visualization or mapping (Pollack and Adler, 2015). This technique is a quantitative method that applies bibliometrics to published literature; it is used to map the structure and evolution of numerous subjects based on large-scale scholarly data sets (Börner et al., 2003). Through network modeling and visualization, scientometric research aims to analyze the intellectual landscape of a knowledge domain and perceive questions that researchers have been attempting to answer, as well as methods that they have developed to achieve their goals (Chen, 2006). Visualizing the entire 
135

MA-BIM provides an approach to acquire a global perspective of research patterns and trends in the field.

The MA-BIM literature provides tangible evidence of the developments in this field, which can lead to conclusions on influential studies that drive BIM adoption, implementation, and post-evaluation, as well as the managerial areas where these works are embodied. The size and scope of the MA-BIM field have expanded, which makes it considerably beyond the reach of manual and intellectual analysis. The techniques required to undertake rapid and effective analysis belong to the domain visualization toolkit, such as CiteSpace, Science of Science (Sci2 Tool), and BibExcel (Chen et al., 2011). In this quantitative interpretivist research, CiteSpace software is used for network analysis and visualization based on the terms that the authors have used to describe their publications.

Keywords and abstracts are considered as clear and concise descriptions of research contents, which necessitates using such terms as units of analysis to identify prominent groupings that affect the structure of the MA-BIM field. In this study, the MA-BIM literature was analyzed in terms of keywords and abstract terms to retain the opinion of the authors as much as possible. And the keyword co-occurrence analysis, keyword burst detection, and abstracts cluster analysis were employed to reveal the research patterns and trends in the MA-BIM field.

Firstly, the keyword co-occurrence analysis makes an aggregate representation of the MA-BIM field, and the indicators of keyword co-occurrence network provide evidence for the subsequent cluster analysis. Secondly, the keyword burst detection shed further insight on the relative change of significance between keywords over time to identify the research trends 
157

158

159

of MA-BIM, in contrast to the keyword co-occurrence analysis that merely presents a static description of the field as a whole, Thirdly, the abstracts cluster analysis indicates the research patterns of the MA-BIM field in detail, and various specific research themes associated with each principal area are identified, which lays the foundation for the establishment of MA-BIM conceptual framework.

\section{The keyword co-occurrence analysis and burst detection}

\subsection{The keyword co-occurrence network}

The selected 126 MA-BIM papers were analyzed in terms of keywords. Four common keywords were noted, namely, "building information modeling," "building information modelling," "building information model," and "BIM." These keywords were defined as the domain stop-words because they form a high percentage in the analysis domain ( $\mathrm{Hu}$ and Zhang, 2015). These four stop-words were excluded because they did not add value to the current study, as well as influenced cluster accuracy of keyword co-occurrence network.

Moreover, not all the keywords provided by the authors were determined to be normalized; thus, the extracted keywords were normalized to ensure consistent treatment of unifying synonyms. As shown in Table 2, "information technologies" was replaced with "information technology" and "construction projects" was replaced with "construction project", and so on. Börner (2010) described that “...80\% effort in scientometric research is spent on data acquisition and preprocessing." After data acquisition and preprocessing, analyses of keyword co-occurrence, keyword burst detection, and abstracts cluster were conducted.

Insert Table 2 about here

Keyword co-occurrence network analysis was performed using CiteSpace. The overall 
network characterizes the development of MA-BIM over time and showed the most important footprints of this field. Nodes in the network represented individual keywords used to generalize the essence of each article. Edges that connect nodes were co-occurrence links, wherein two different keywords were used together in the same article.

Table 3 indicates the overall characteristics of the keyword co-occurrence network. In particular, modularity Q and mean silhouette scores are two significant metrics that determine the overall structural properties of the network. It is notable that a modularity Q of 0.8115 is relatively high $(\mathrm{Q}>0.3)$, which indicates that the network is reasonably divided into loosely coupled clusters (Newman, 2006). A mean silhouette score of $0.9372(>0.7)$ suggests that the homogeneity of these clusters is also relatively high, which indicates that network cluster is efficient and reliable (Kaufman and Rousseeuw, 2009). The results provide the basis for ensuring usefulness and credibility of datasets in the succeeding work.

Insert Table 3 about here

The overall keyword co-occurrence network is shown in Fig. 2. Node size represents the frequency at which a keyword occurs, whereas edge weight represents the frequency at which two keywords are used jointly. The colors of these lines are designed to show when a connection is made among different keywords for the first time. The color encoding clarifies which part of the network is old and which one is new. Fig. 2 indicates that blue represents the keywords connected for the first time in 2007, whereas orange represents the connections of keywords in 2015. Color transition from a cool tone to a warm tone represents the timespan from past to present.

Insert Fig. 2 about here 
The timespan set for the present study in CiteSpace is from 2007 to 2015, which is related to the size of dataset (Chen, 2014). After searching from WoS and Scopus within "all years" as well as delimitation process as introduced in Section 2.1, the dataset of this study that included 126 papers published from 2007 to 2015 were identified and considered as recent work. The concept of BIM can be traced back to the "building description systems" proposed by Eastman in the mid-1970s (Eastman, 1976). It is acknowledged that the 126 identified papers do not include all publications that contribute to MA-BIM research to date. However, 16 selected journals include the most prominent publications relevant to MA-BIM. The 126 identified papers were considered sufficient to represent the latest developments in the last decade as a whole.

Fig. 3 highlights the most frequently occurring keywords. The frequency of "information technology" is the highest, which represents the physical attribute of BIM. As a major shift in information technology during the last decade, BIM, which refers to both the activity of modeling and the digital and virtual models of a building, triggers the transformation of the project management paradigm (Succar, 2009). Other keywords that relate to "information technology" also include "information system" and "information management." The proximity of the keywords "education," "engineering education," and "adoption" aligns with the expectation of an association between these topics. Hartmann and Fischer (2008) concluded that "far-reaching education and training programs" are required to achieve extensive BIM adoption. Similarly, arriving at conclusions regarding the association of other keywords based on their placement is possible. For example, "integration," "coordination," and "lean construction" are distributed on the bottom left side of Fig. 3. Lean construction and 
BIM are relatively different initiatives, but are inextricable part of each other. The integration and coordination between these two initiatives can be maximized to improve project processes beyond the degree to which such processes may be improved by the independent application of either of these paradigms (Sacks et al., 2010). On the one hand, construction projects on a lean journey are contingent on BIM to enhance the lean outcomes. On the other hand, changes in business processes as a consequence of BIM implementation significantly contribute to make a project considerably lean. Based on the placement, issues associated with design and construction appear to be highly associated with information technology, whereas issues associated with operation and maintenance are lacking. Although the review of BIM literature indicates an increasing interest in facility management, a considerable divide remains between the studies that focus on new construction and existing buildings. Insert Fig. 3 about here

Keyword co-occurrence network is a static representation of a specific field that has not considered changes over time in the manner in which the terms are used. However, CiteSpace provides a time zone perspective that each term is arranged in chronological order to show development trends and interactions among keywords. As shown in Fig. 4, the evolution of MA-BIM-related keywords continued from 2007 to 2015. The lines that connect nodes are co-occurrence links between different keywords. The colors of these lines are designed to show when a connection has been made for the first time. Given the transformation of BIM from $3 \mathrm{D}$ to $\mathrm{nD}$, keywords unsurprisingly veer away from "collaborative design" to "construction safety," "cost," and "energy." Increasing interests are emerging on "change management," "information technology strategy," and "team working" in 2015. By contrast, earlier keywords tend to focus on specific implementation process in relation to MA-BIM, 
such as "implementation", "design process" and "process improvement", which potentially indicate a change from a tactic focus to an emphasis on strategy. This change may also be partly caused by the increasing complexity of construction projects, particularly emerging mega construction projects (MCPs), which leads to high project uncertainty, complex stakeholder interrelationships, and conflicting interests. It should be noted that keywords co-occurrence taken in isolation can lead to misinterpretation if taken out of context (Pollack and Adler, 2015). In this study, it is essential to refer to specific articles using these keywords to avoid ambiguity.

Insert Fig. 4 about here

\subsection{The keyword burst detection}

Keyword co-occurrence analysis through network mapping provides several insights into the MA-BIM field. However, the process of keyword frequency change with time remains unclear. A keyword burst provides evidence that a particular keyword is associated with a surge of occurrence frequency. Accordingly, a keyword burst is considered an indicator of a highly active research area that represents changes in significance among keywords from a historical perspective. As a function in CiteSpace based on Kleinberg's bursty and hierarchical structure in streams (Kleinberg, 2003), keyword burst detection can be used in the present study to explore emergent trends and passing fads within the MA-BIM field (Pollack and Adler, 2015). Evidently, the bursting keyword has attracted an unusual degree of attention from the research community during a specific period. Fig. 5 shows a visualization of the keyword burst analysis in the MA-BIM field from 2007 to 2015; the top 25 bursting keywords are also shown, as sorted based on their beginning year of burst. 
The burst detection algorithm indicates unusually large changes in the frequency of a datum over time (Pollack and Adler, 2015). For example, with the proliferation of 4D, 5D, or nD BIM, the keyword "three-dimensional models" was barely part of the common terms at present. Since 2007, a robust growth was observed in the "three-dimensional models" use for construction project management. After 2010, the term "three-dimensional models" became common, although of a relatively high frequency compared with that in the $2000 \mathrm{~s}$, and would no longer be considered to be bursting because it already reached a steady state.

Fig. 5 shows that the keywords "change management," "information technology strategy," "maintenance," "design errors" and "team working" have continued bursting from 2007 to 2015, which is consistent with the findings of the timeline view in Fig. 4. This case is unsurprising based on the results of keyword burst detection. For example, as MCPs emerged in multitude, their extreme uncertainty and complexity resulted in cost overruns and time delay, which led to the demand for efficient change management and the minimization of design errors. Similarly, research focus shifts from design to maintenance (Becerik-Gerber et al., 2011), particularly of complex construction projects, which is also in line with the analysis results in Fig. 5. It is noteworthy that keyword burst detection may indicate an emphasis away from individual-centered issues to a broad organizational perspective in general. This case highlights the importance of "team working", "collaborative design" and “organizations." In addition, MA-BIM hotspots and frontiers are also identified based on keyword burst detection, particularly on frequency changes occurring within the last five 
development," "information system," "adoption," "modelling," and "education."

\section{The abstract term cluster analysis}

\subsection{Summary of abstract term cluster analysis}

A keyword co-occurrence network provides several general insights into the MA-BIM field. However, frequency and timeline analyses fail to clarify major areas and structures of MA-BIM studies. As a mathematical and statistical method, cluster analysis is used to identify the latent semantic themes within the textual data (Hossain et al., 2011). Cluster analysis employs a set of algorithms to convert unstructured text into structured data objects to detect research patterns for the discovery of knowledge (Delen and Crossland, 2008). The main idea behind cluster analysis is to collect all the contexts belonging to the words in the literature dataset, and derive associated clusters that represent related research themes (Yalcinkaya and Singh, 2015). Therefore, cluster analysis can be used to identify several prominent groupings, and has been adopted in this study to show research patterns in the MA-BIM field.

As a tool for progressive knowledge domain visualization, CiteSpace provides various functions to facilitate the understanding and interpretation of network patterns, including decomposing a network into clusters and automatic labeling clusters with terms from the titles, keywords, or abstracts (Chen, 2006). Apart from keywords, titles and abstracts are also typically used by authors to describe a publication. Ultimately, abstracts are taken as a unit of cluster analysis because they provide the complete expression of research contents, and consequently, reliable indicators of theme-divisions in the MA-BIM field. To characterize the nature of an identified cluster, CiteSpace can automatically extract noun phrases from the 
abstracts based on a set of algorithms, including frequency-inverse document frequency (tf*idf), log-likelihood rate (LLR) and mutual information (MI) (Chen, 2014). Each cluster reserves and represents a certain amount of the overall observed terms, and the clusters are organized in the order of how many terms they explain. Fig. 6 shows that the clusters are numbered in descending order of cluster size, starting from the largest cluster $\# 0$, the second largest \#1, and so on. And this is the default naming patterns of clusters in CiteSpace.

Insert Fig. 6 about here

Overall, MA-BIM has 8 prominent research clusters; each cluster can be regarded as a research theme. These themes are relatively independent of one another, as well as partially overlapping. In any text, multiple words may share the same meaning and one word may have many synonyms in different contexts. Cluster analysis "loads" the words that share the same meaning to their associated theme and also "loads" one word to various latent semantics other than its main associated theme (Yalcinkaya and Singh, 2015). Thus, there is the case that some of the clusters are overlapping. In other words, some of the abstract terms belong to several clusters at the same time.

It is notable that the automatic labeling clusters can lead to misinterpretation if their labels are taken out of context. As mentioned earlier, one word may bring out various meanings in different contexts. It is thus necessary to refer to the specific abstract terms of each cluster to resolve this. Three to five abstract terms with top frequencies were, therefore, selected to represent the theme-clusters because they were most likely to be selected and used by the researchers in each cluster. And the names of each cluster were further refined by referring to the individual articles using these high-frequency abstract terms, with a view to avoiding and 
eliminating the ambiguity of the automatic labels generated by CiteSpace. Table 4 shows the cluster size and representative terms of each theme-cluster. Cluster size refers to the number of abstract terms involved for each cluster, and the silhouette shows the homogeneity of a cluster as mentioned in Section 3.1. The higher the silhouette score, the more consistent the cluster members. Unlike most previous studies based on the subjective understanding of a specific field from authors, abstract term cluster analysis provides a more objective approach to perceive the overall structure of a certain knowledge domain.

Insert Table 4 about here

\subsection{Detailed MA-BIM research themes}

\subsubsection{Collaborative working environment}

Cluster $\# 0$ is related to the research of collaborative working embedded into various environments. In the current digital economy, the construction industry is on the verge of a technological revolution. The main trajectories that characterize the development and application of digital technologies include visualization, collaboration, automation, integration, and transformation (Hassan, 2013). BIM appears to be the emerging leading paradigm, which should be considered a dynamic process rather than a model per se, thereby supporting collaborative working environments for involved parties during the overall project life cycle. As a backbone for collaboration, interoperability in relation to BIM is not only a technical issue, but also concerns business processes, culture, values, and management of contracts between interacting parties. To achieve significantly high value levels in the construction industry, changes in interoperability are required to depart from "efficiency and differentiation" to "value innovation;" these changes are emerging with the design of new 
3D-based collaborative environments that sustain creativity and also through a complete dematerialization and reconfiguration of traditional processes within cross-organizational construction projects (Grilo and Jardim-Goncalves, 2010).

Apart from interoperability, collaborative working using BIM also demands new expert roles of model managers who possess information and communications technology (ICT) and construction process expertise (Sebastian, 2011). It is hard for a BIM manager to be involved neither in decision making on design and engineering solutions nor in project management processes but mainly focuses on model specification and information management. In many cases, managerial hierarchy also exists among BIM managers, which leads to some differences in their organizational roles. Furthermore, changing roles in collaborative work that applies BIM affect the traditional contractual relationship, particularly payment schemes.

Given that engineering work is done concurrently with the design through BIM, for example, a new payment percentage in the early design phase is also necessary (Chao-Duivis, 2009).

\subsubsection{Innovation}

Cluster \#1 refers to the studies on innovation during the BIM diffusion process. Within the construction industry, innovation is infamously known to be difficult to define and conceptualize (Green et al., 2004). However, the concept of innovation is certain to be further related with the espoused change in the construction industry, which is renowned for its adversarial relationship and lack of trust among involved parties. Elmualim and Gilder (2014) investigated the relationship among design management, innovation, and the role of BIM in advancing collaboration in response to the required change. The innovation and the application of emerging technologies are considered as enablers for transforming the project 
delivery process and adding value across the entire project life cycle. Two main innovation processes are involved with regard to the use of BIM as an innovative technology, namely, innovation adoption and implementation.

Innovations take time to become extensively adopted because of insufficient referential experiences ( $\mathrm{Gu}$ and London, 2010). BIM is a relatively complex and influential innovation (Eastman et al., 2011), and the general rate of BIM adoption is still much lower than expected (Cao et al., 2015). To explore the internal mechanism of varying levels of BIM adoption, Linderoth (2010) considered the diffusion of BIM as the transfer and spread of innovations that are occurring in networks of actors linked to one another. The roles and relationships of actors in a network relate to their potential motives for accepting or rejecting BIM. Furthermore, Singh and Holmström (2015) investigated innovation-related decisions from the viewpoint of Maslow's motivational theory on the hierarchy of needs, which developed insights into the psychological processes that underlie the motivation to adopt BIM.

Along with BIM implementation, innovations are constantly emerging in this process to improve management efficiency. Numerous variations of BIM technology arises at different implementation stages to enhance information management efficiency performance and facilitate the accomplishment of established project goals, including "site BIM," "green BIM," and "cloud BIM." Davies and Harty (2013) applied an innovative "site BIM" system in a major hospital construction project based on BIM-enabled tools that allow site workers to use mobile tablets to access design information and acquire work quality and progress data synchronously. "Green BIM" has become a tremendously popular term and concept in recent years; it is applied to both building sustainability analysis and design management, as well as 
construction stages; the goal of this process also extends to the entire life cycle of a building, including the operation (commissioning and occupation), repair and maintenance, and demolition stages (Wong and Zhou, 2015). Cloud computing refers to both the applications delivered as a service over the Internet and the hardware and system software in data centers that openly interoperate and exchange information (Armbrust et al., 2010). Cloud-based BIM serves as an innovative platform that will enhance BIM usability experience for various disciplines in making key design decisions at a relatively early project stage (Redmond et al., 2012).

\subsubsection{Stakeholder/actor network}

Cluster \#2 is related to the analytical perspective of the stakeholder or actor in BIM adoption and implementation studies. As a "system" of multiple innovations, BIM generates derived benefits to those involved in its implementation, but is also associated with the potential for failures (i.e., cost overruns, and legal disputes). Gilligan and Kunz (2007) conducted a survey to determine the value of BIM to project stakeholders, which mainly referred to reducing risks for stakeholders distributed across the project and to engage stakeholders further. By contrast, BIM has been challenged with the issues regarding stakeholder collaboration and the manner of managing and controlling information (Sebastian, 2011). Murphy (2014) explained that the mechanism problem exposed in BIM implementation was based on BIM currently being delivered as a project rather than an innovation, as well as the failure to address stakeholder competency as the key delivery agent of BIM.

Apart from the research that focuses on the individual level, the organizational-level 
research related to the overall structure and characteristics of the actor network in which BIM is applied provides a holistic approach to determine how BIM defines roles and relationships among actors in a network (Linderoth, 2010), as well as how and why project networks respond to new systemic innovations (i.e., BIM) that are misaligned to the existing network structure (Alin et al., 2013). Moreover, the overall network approach suggests a need to rethink actor interlinkages and interorganizational effects (i.e., task sequence alignment, knowledge base alignment, and work allocation alignment), as well as to create new roles associated with the implementation of BIM in construction projects.

\subsubsection{Spatial visualized management}

Cluster \#3 refers to the studies related to spatial visualized management using BIM in construction projects. ICT changes architectural visualization by extending architectural design to visualization in information systems and by applying highly extensive computer visualization given the availability of digital media (Koutamanis, 2000). Architectural visualization plays a significant role in managing complicated interactions among involved parties to balance all types of constraints and requirements (Wang et al., 2014). As a digital representation of the physical and functional characteristics of a building, BIM fosters multi-dimensional visualization capabilities to communicate ideas and share information among various stakeholders in construction projects (Johansson et al., 2015). The application and development of BIM in the spatial visualized management of a project are embodied in two significant methods.

The first method is the integration of BIM with augmented reality (Wang et al., 2013), a geographic information system (GIS) (Irizarry et al., 2013), and a wireless sensor (Riaz et al., 
2014), which extends the limits of visualized management, with the attempt to fill in the technical gap. The second method concerns the synergy between BIM and lean philosophy to provide process transparency to all participants and to pull the flow of teams and materials (Sacks et al., 2009). Given the dynamic and dispersed physical environments and the complicated contracting interfaces of construction projects, efficient and reliable visualized management is based on addressing technical solutions and on improving management-centered processes. This process highlights the importance of bridging both technical and non-technical issues to create the enabling environment of real-time autonomous decision making within highly variable project information flows.

\subsubsection{BIM adoption}

Cluster \#4 covers the issues that focus on adoption activities in BIM implementation process. Although the potential benefits of technologies may appear evident in BIM, the industry adoption level of this process varies extensively, and the actual diffusion rate of technology among involved parties worldwide remains considerably lower than expected $(\mathrm{Gu}$ and London, 2010). Such a discrepancy between expected adoption and the realized adoption of BIM may be explained by the uncertainty of its value and effectiveness. By considering the possible gap among technical feasibility, potential value, and practical adoption, increasing research interests and efforts are presented to examine the degree by which BIM is currently adopted through the life cycles of construction projects in different countries or regions (Cao et al., 2015; Samuelson and Björk, 2014; Mahalingam et al., 2015; Imoudu Enegbuma et al., 2014), as well as the factors that drive BIM adoption in various types of organizations (Aibinu and Venkatesh, 2013; Son et al., 2015). The studies on investigating BIM adoption 
can be placed at three levels: the individual/actor, the project/organization, and the entire market/industry.

The initial decision for BIM adoption has mostly been considered at the individual level, or occasionally, at the organization level, and for single actors in the industry (Samuelson and Björk, 2013). It is noteworthy that individual-level studies mainly revolve around technology acceptance behavior-related theories, including theory of planned behavior (TPB), technology acceptance model (TAM), and task-technology fit model (TTF). These theories put considerable emphasis on the behavioral intentions of individuals. For the project/organization level, the most prominent studies of BIM adoption include those on the practices and effectiveness of BIM in construction projects in China (Cao et al., 2015) and where to focus on the successful adoption of BIM within an organization (Won et al., 2013). In summary, these findings identify numerous factors that drive or impede BIM adoption at both the individual and project levels. These factors can be further grouped into three dimensions, namely, technical and non-technical, institutional and non-institutional, and internal behavioral intentions and external environment.

Regarding the market level, Succar and Kassem (2015) introduced a number of macro-adoption models, matrices, and charts to assess BIM adoption across markets systematically, as well as to inform the structured development of country-specific BIM diffusion policies. Based on the industry level, Gu and London (2010) analyzed the readiness of the industry with respect to the products, processes, and people to position BIM adoption in terms of the current status and expectations across disciplines. The aforementioned studies also established the collaborative BIM decision framework to facilitate BIM adoption in the 
construction industry. Both market- and industry-level studies provide the holistic conceptual framework to facilitate decision making, particularly for policymakers, within the BIM diffusion process.

\subsubsection{Transmission}

Cluster \#5 refers to the studies that focus on culture or policy transmission related to BIM through the project life cycle, which is closely associated with cluster 4; however, the two clusters have different priorities. BIM adoption is suggested to pay increased attention to individual-level decision making in light of behavioral intentions. By contrast, culture or policy transmission actually focuses on the BIM diffusion process, which highlights the importance of creating the enabling environment to drive large-scale applications of BIM.

From the cultural transmission perspective, Brewer and Gajendran (2012) determined the link among culture formation, culture development, and their effects on using BIM in temporary project organization (TPO), which illuminated the positive cultural traits demonstrated by the specialist subcontractor.

Policies are "written principles or rules to guide decision making," which results in environmental pressures (i.e., preparatory, regulatory, and contractual requirements) to project decision makers in terms of acquiring institutional legitimacy. Succar (2009) introduced an integrated framework that treated policy as one of the three major fields of BIM to provide a research and delivery foundation for BIM diffusion policy development. Furthermore, Succar and Kassem (2015) provided a "policy action model" by which the actions that policymakers take to facilitate market-wide diffusion are identified, assessed, and compared, thereby informing the macro-environment of country-specific BIM adoption 
policies. These findings suggest that BIM diffusion is a highly socialized and complicated activity that may be motivated by individual behavioral intentions to improve the efficiency and effectiveness of the design, construction, and operation processes. This activity may also be driven by cultural and policy transmission to be in line with its specific external environment.

\subsubsection{Conceptual framework}

Cluster \#6 is related to the development of a conceptual framework in MA-BIM studies. To analyze MA-BIM, a few conceptual frameworks are proposed to represent domain concepts and their relations, which can be divided into two types, namely, strategic- and tactical-level frameworks. A strategic-level framework mainly focuses on the conceptual system, diffusion, and adoption of BIM from a macroscopic perspective regardless of detailed implementation steps. A tactical-level framework is concerned with the BIM application process, which aims to provide a specific approach to overcome technical, procedural, and organizational challenges.

At the strategic level, Succar (2009) introduced a series of conceptual frameworks to structure the term "BIM" in a stepwise manner, including BIM fields, BIM maturity stages, and BIM lenses. With the proliferation of BIM concepts through project organizations, a few strategic assessment frameworks are introduced to recognize BIM "value proposition," inform the status of BIM implementation, and evaluate BIM diffusion policies based on the need for guidance on the place to start, the tools available, and working through both technical and non-technical issues.

At the tactical level, numerous conceptual frameworks were proposed to integrate BIM 
with other technologies or business processes to provide implementation approaches. Varying levels of understanding, adoption, and implementation of BIM within and among countries exist-from discipline to discipline and from project to project. The challenges to achieve a completely integrated collaborative multi-disciplinary platform of implementation is based on determining technical solutions or addressing MA-BIM issues, as well as on setting up the enabling conceptual framework, which integrates both strategic- and tactical-level approaches.

\subsubsection{Operation and Maintenance}

The research themes of cluster \#7 concentrate on the operations and maintenance (O\&M) stage in BIM implementation process. It is noteworthy that the use of BIM focuses on the preplanning, design, and construction of buildings and infrastructure; however, the focus of recent research has shifted from early life cycle stages to maintenance, refurbishment, and deconstruction (Volk et al., 2014). The long building life cycles has resulted in O\&M management that becomes a major to exploit the functionalities and benefits of BIM fully, particularly in relation to environmental performance monitoring and management using virtual prototyping/visualization tools. Therefore, an increasing number of studies are emerging, which aims to explore how BIM can be a beneficial platform to supplement O\&M practices. The two major dimensions that are centered on the research themes of cluster \#7 are building types (e.g., new buildings and existing buildings) and application areas (e.g., energy/thermal analysis and control, space management, refurbishment/renovation planning and execution, quality assurance and control).

Within the dimension of building types, Volk et al. (2014) explained that with a decrease in 
new construction rates worldwide, particularly in industrialized countries, existing buildings would become the main application field of BIM. Unlike new buildings (e.g., buildings under construction, and recently completed buildings), existing buildings without preexisting BIM face the considerable challenges of automatic data capture and BIM creation, along with the handling and modeling of uncertain data, objects, and relations. The limitations of BIM use in the O\&M stage of existing buildings call for future research efforts.

For the dimension of application areas, Becerik-Gerber et al. (2011) conducted an online survey and face-to-face interviews to assess the current status of BIM implementations in the O\&M stage, potential applications, and the interest level in the utilization of BIM, which highlighted the synergy between BIM and O\&M in terms of data requirements. Moreover, resource scarcity and highly strict decrees for recycling and resource efficiency in construction projects have awakened the construction industry to the importance of enhancing environmental sustainability through emerging new technologies (i.e., 'green BIM'). Therefore, BIM-based environmental performance management is among the highly important application areas in O\&M stages. Wong and Zhou (2015) stated that a “one-stop-shop" BIM for environmental sustainability monitoring and management over the entire life cycle of a building should be considered in future studies, particularly during building maintenance, retrofitting, and demolition stages. Based on the aforementioned problems and challenges, "green BIM" and BIM-enabled existing building management seem to be the most important directions for future O\&M studies. 


\section{The conceptual framework for MA-BIM}

575

\subsection{Introduction to MA-BIM conceptual framework}

The scientometric analysis of MA-BIM provides supporting elements to this study in its objective to develop an integrated framework. Although the framework is currently conceptual, the scientometric analysis of the overall structure, theme-divisions, and emergent trends, along with the practical experiential knowledge, of MA-BIM makes this framework both practical and enlightening.

Fig. 7 shows that the conceptual framework has three major parties, namely, current status, research areas, and future directions. Instead of applying an a priori classification approach, this paper conduct a quantitative analysis based on the abstract terms to distinguish different research themes. And 8 theme-clusters are further integrated into 5 research areas according to the framework developed by Gu and London (2010). It is noteworthy that this framework summarizes the perceptions of BIM from the perspective of product, process, and people, and also emphasizes the importance of creating the enabling environment of BIM management and choosing suitable application approaches to fulfill BIM potential.

Insert Fig. 7 about here

BIM adoption leads to substantial changes in the existing project management processes, involving innovation diffusions, culture and policy transmissions. In parallel with the rapid popularization of BIM technologies, a series of "soft" products (i.e., conceptual frameworks) have emerged to provide support and guidance for BIM implementation. And stakeholders and actors are people whose roles associate with BIM practices. It is noteworthy that collaborative working environment refers to the external context in relation to BIM, and 
596

597

598

599

600

601

602

603

604

605

606

607

608

609

610

611

612

613

614

615

spatial visualized management and O\&M are particularly concerning issues when choosing suitable application approaches of BIM. Fig. 8 summarizes the 5 principal research areas of MA-BIM at a broad level, and shed further light on their inter-relationships. The implications and inter-relationships of 8 theme-clusters are further described on the basis of 5 research areas of MA-BIM as follows.

Firstly, conceptual framework (\#6) can be regarded as a managerial product to structure strategies and implementation approaches against MA-BIM issues. Secondly, innovation (\#1), BIM adoption (\#4), and transmission (\#5) are interrelated and interact on each other in the BIM diffusion process. Thirdly, new roles and relationships within the project teams are emerging through the BIM adoption and implementation process. And stakeholder or actor (\#2) is the implement subject of BIM throughout the project life cycle. Fourthly, spatial visualized management $(\# 3)$ is the application way of BIM in relation to managerial aspects (i.e., lean philosophy). O\&M (\#7) becomes the most potential stage for future MA-BIM research as mentioned in Section 4.2. Both of application way and stage for this study is summed up in one aspect-'application approach', with a view to focusing on the way of realization for MA-BIM benefits. Finally, collaborative working environment $(\# 0)$ is regarded as the ideal external condition to be achieved for MA-BIM. Through the lens of the aforementioned 5 principal research areas, the current status and future directions of MA-BIM are further discussed as follows. 


\subsection{Detailed elements of MA-BIM conceptual framework}

617

\subsubsection{Conceptual framework}

The conceptual framework corresponds to cluster \#6 (conceptual framework), which can be divided into two levels (i.e., strategic and tactical). Apart from the adoption and diffusion of BIM, developing strategic-level frameworks for the post-evaluation process in view of tracking BIM application performance throughout the project life cycle is useful. It is notable that the applicability of tactical-level frameworks should be regarded within different organizational and regional contexts. Contextual factors (i.e., organizational model, institutional pressures, and cultural environment) exert substantial implications on the manner by which stakeholders engage in BIM adoption and implementation processes. Despite the close association between MA-BIM framework and contextual factors, there is still a lack of studies exploring this issue and its impact. A substantial proportion of existing literature has ignored contextual differences and endeavored to establish MA-BIM frameworks which are universal across organizational and regional boundaries. Therefore, future research in this field could bring insightful and beneficial results.

\subsubsection{Adoption process}

The adoption process relates to clusters \#1, \#4, and \#5 (i.e., innovation, BIM adoption, and transmission, respectively), which involve the spread of innovation, cultural and policy transmission, technology acceptance behavior-related theories, and influential factors of BIM adoption. In future studies, leadership theory and psychological factors can be considered for empirical studies in terms of individual BIM adoption process. For instance, empirical studies can be undertaken to explore the influences of different styles of leadership (e.g., 
transformational leadership and transactional leadership) and psychological capital on the individual BIM adoption process. Moreover, exploring the influences of organizational inertia on BIM adoption process is also necessary. For the market-level BIM adoption, the influences of regional differences (e.g. culture variances and institutional environment) cannot be ignored.

\subsubsection{Stakeholder and actor}

The stakeholder and actor refers to cluster \#2 (stakeholder/actor network), which concerns stakeholder competency, stakeholder collaboration, and actor networks. Successful BIM adoption and implementation process requires fully considering and effectively balancing stakeholder interests relations and priorities of concerns. Notwithstanding the significance of analyzing stakeholder interrelationships in project organizations, existing MA-BIM research in relation to stakeholder or actor has paid inadequate attention to quantitative measurement of stakeholder network characteristics. In future research, social network analysis (SNA) can be undertaken to reveal the overall structure (e.g., density and cohesive subgroup) and relational ties (e.g., expressive ties and instrumental tie) of stakeholder network. By identifying the key stakeholder (e.g. opinion leader) through SNA assessment, the leadership influences could be better exercised to facilitate BIM adoption and implementation. In addition, external environment factors (e.g., institutional pressure) also need to be given attention in project networks analysis.

\subsubsection{Application approach}

The application approach corresponds to cluster \#3 (i.e., spatial visualized management, and O\&M, respectively), which focuses on the way (stage) to achieve BIM's capabilities in 
managerial areas. Currently, real-time information visibility and traceability still falls short of expectations partially because of the complex physical conditions of construction sites and fractured contract interfaces. Therefore, future studies in this area will synchronize visualized management with ongoing project processes in a real-time manner. Combining visualized management with risk scenario planning is also necessary to remove lurking perils beforehand. In addition, increasingly serious worldwide environmental problems and numerous buildings without preexisting BIM in the design and construction stages stimulate research interests related to "green BIM" and existing BIM-enabled building management.

\subsubsection{Working environment}

The working environment relates to cluster \#0 (collaborative working environment), which involves interoperability, as well as changing roles in collaborative working. The efforts for interoperability of the construction industry have been highly focused on technical issues of connecting systems and applications among the involved parties. It is noteworthy that widening the technically focused view of interoperability is required to cover business processes and contractual management in creating a collaborative working environment. The concept of organizational climate is a particularly useful indicator to characterize MA-BIM working environment. In future research, empirical studies can be undertaken to analyze the practical implications of different types of organizational climate (e.g., empowerment climate, ethical climate) for the success of BIM adoption and implementation.

\section{Conclusions}

BIM technology and its increasing use are prompting several profound changes in business processes and project management practices. As the technical side of BIM evolves, new roles 
682

683

and relationships within project stakeholders, along with various project delivery systems (i.e., IPD, IPD-ish, or IPD-lite), are constantly emerging. The managerial areas of BIM have been attracting considerable attention from both the construction industry and academia because of the potential of this area in coordinating and managing overall project information and processes, as well as aligning organizational strategies within a complex project environment.

This study has drawn findings from a body of literature comprising 126 papers published in 16 academic journals, in response to the search term "MA-BIM." A variety of scientometric techniques are used to analyze changes in MA-BIM studies published between 2007 and 2015, including keyword co-occurrence network, keyword burst detection, and abstract term cluster analysis.

The keywords and abstracts have been analyzed in terms of the co-occurrence and rate of frequency change of keywords, and semantic grouping of abstract terms. Firstly, the keywords are used to construct co-occurrence network maps of the field as a whole. Secondly, future directions are identified in the MA-BIM field using keyword burst detection, which indicate a paradigm shift from tactic focus to an emphasis on broad strategy, as well as from individual-centered issues to a broad organizational perspective. Thirdly, the abstract term cluster analysis reveals 8 prominent research themes in the MA-BIM field, namely collaborative working environment, innovation, stakeholder/actor network, spatial visualized management, BIM adoption, transmission, conceptual framework, and O\&M.

Based on the scientometric analysis, this study has further developed an integrated conceptual framework for MA-BIM to refine the 8 theme-clusters into 5 key aspects, with the objective of providing structured means of describing current status and future directions. The 
traditional BIM adoption analysis, which emphasizes individual behavior intentions, has been extensively used in MA-BIM regardless of leadership factors and organizational inertia. This scientometric analysis of MA-BIM is significant and invaluable in allowing bibliometric data to provide a highly accurate representation of previous research efforts, as well as in illustrating a future research direction for this field.

\section{Acknowledgment}

This study is jointly supported by the National Natural Science foundation of China (Project No.: 71571137 and 71390523) and the International Exchange Program for Graduate Students in Tongji University. The authors would like to acknowledge Professor Yongkui Li, Tongji University, and Doctor Giorgio Locatelli, the University of Leeds, for their valuable opinions and suggestions.

\section{References}

Aibinu, A., \& Venkatesh, S., 2013. Status of BIM adoption and the BIM experience of cost consultants in Australia. Journal of Professional Issues in Engineering Education and Practice, 140(3), 04013021.

Alin, P., Maunula, A. O., Taylor, J. E., \& Smeds, R., 2013. Aligning Misaligned Systemic Innovations: Probing Inter - Firm Effects Development in Project Networks. Project Management Journal, 44(1), 77-93.

Armbrust, M., Fox, A., Griffith, R., Joseph, A. D., Katz, R., Konwinski, A., ... \& Zaharia, M., 2010. A view of cloud computing. Communications of the ACM, 53(4), 50-58.

Barlish, K., \& Sullivan, K., 2012. How to measure the benefits of BIM-A case study approach. Automation in construction, 24, 149-159.

Becerik-Gerber, B., Jazizadeh, F., Li, N., \& Calis, G., 2011. Application areas and data requirements for BIM-enabled facilities management. Journal of construction engineering and management, 138(3), 431-442.

Börner, K., Chen, C., \& Boyack, K. W., 2003. Visualizing knowledge domains. Annual review of information science and technology, 37(1), 179-255.

Börner, K., 2010. Atlas of Science: Visualizing What We Know. MIT Press, London.

Brewer, G., \& Gajendran, T., 2012. Attitudes, behaviours and the transmission of cultural traits: Impacts on ICT/BIM use in a project team. Construction Innovation, 12(2), 198-215.

Bryde, D., Broquetas, M., \& Volm, J. M., 2013. The project benefits of building information modelling (BIM). International Journal of Project Management, 31(7), 971-980. 
Cao, D., Li, H., \& Wang, G., 2014. Impacts of isomorphic pressures on BIM adoption in construction projects. Journal of Construction Engineering and Management, 140(12), 04014056.

Cao, D., Wang, G., Li, H., Skitmore, M., Huang, T., \& Zhang, W., 2015. Practices and effectiveness of building information modelling in construction projects in China. Automation in Construction, 49, 113-122.

Chao-Duivis, M., 2009. Legal implications of working with BIM. Tijdschrift voor Bouwrecht, 44, 204-212.

Chen, C., 2006. CiteSpace II: Detecting and visualizing emerging trends and transient patterns in scientific literature. Journal of the American Society for information Science and Technology, 57(3), 359-377.

Chen, C., 2014. The CiteSpace Manual. Retrieved 31 August, 2015, from http://cluster.ischool.drexel.edu/ cchen/citespace/CiteSpaceManual.pdf.

Chen, K., Lu, W., Peng, Y., Rowlinson, S., \& Huang, G. Q., 2015. Bridging BIM and building: From a literature review to an integrated conceptual framework. International Journal of Project Management.

Chen, Y. W., Fang, S., \& Börner, K., 2011. Mapping the development of scientometrics: 2002-2008. Journal of Library Science in China, 3, 131-146.

Davies, R., \& Harty, C., 2013. Implementing 'Site BIM': a case study of ICT innovation on a large hospital project. Automation in Construction, 30, 15-24.

Delen, D., \& Crossland, M. D., 2008. Seeding the survey and analysis of research literature with text mining. Expert Systems with Applications, 34(3), 1707-1720.

Eastman, C., 1976. General purpose building description systems. Computer-Aided Design, 8(1), $17-26$.

Eastman, C., Eastman, C. M., Teicholz, P., \& Sacks, R., 2011. BIM handbook: A guide to building information modeling for owners, managers, designers, engineers and contractors. John Wiley \& Sons.

El Asmar, M., Hanna, A. S., \& Loh, W. Y., 2013. Quantifying performance for the integrated project delivery system as compared to established delivery systems. Journal of Construction Engineering and Management, 139(11), 04013012.

Elmualim, A., \& Gilder, J., 2014. BIM: innovation in design management, influence and challenges of implementation. Architectural Engineering and design management, 10(3-4), 183-199.

Elsevier, 2016. Scopus Content Coverage Guide. Retrieved 28 May, 2016, from https://www.elsevier.com/data/assets/pdf_file/0007/69451/scopus_content_coverage_guide.pdf.

Fox, S., \& Hietanen, J., 2007. Interorganizational use of building information models: potential for automational, informational and transformational effects. Construction Management and Economics, 25(3), 289-296.

Gilligan, B., \& Kunz, J., 2007. VDC use in 2007: significant value, dramatic growth, and apparent business opportunity. TR171, 36 .

Green, S. D., Newcombe, R. A., Fernie, S., \& Weller, S., 2004. Learning across business sectors: knowledge sharing between aerospace and construction.

Grilo, A., \& Jardim-Goncalves, R., 2010. Value proposition on interoperability of BIM and collaborative working environments. Automation in Construction, 19(5), 522-530.

Gu, N., \& London, K., 2010. Understanding and facilitating BIM adoption in the AEC industry. Automation in construction, 19(8), 988-999. 
Hartmann, T., \& Fischer, M., 2008. Applications of BIM and Hurdles for Widespread Adoption of BIM. 2007 AISC-ACCL eConstruction Roundtable Event Rep.

Hassan Ibrahim, N., 2013. Reviewing the evidence: use of digital collaboration technologies in major building and infrastructure projects. Journal of Information Technology in Construction, 18, 40-63.

Hossain, M. M., Prybutok, V., \& Evangelopoulos, N., 2011. Causal Latent Semantic Analysis (cLSA): An Illustration. International Business Research, 4(2), 38.

Hu, J., \& Zhang, Y., 2015. Research patterns and trends of Recommendation System in China using co-word analysis. Information Processing \& Management, 51(4), 329-339.

Imoudu Enegbuma, W., Godwin Aliagha, U., \& Nita Ali, K., 2014. Preliminary building information modelling adoption model in Malaysia: A strategic information technology perspective. Construction Innovation, 14(4), 408-432.

Irizarry, J., Karan, E. P., \& Jalaei, F., 2013. Integrating BIM and GIS to improve the visual monitoring of construction supply chain management. Automation in Construction, 31, 241-254.

Johansson, M., Roupé, M., \& Bosch-Sijtsema, P., 2015. Real-time visualization of building information models (BIM). Automation in Construction, 54, 69-82.

Kaufman, L., \& Rousseeuw, P. J., 2009. Finding groups in data: an introduction to cluster analysis (Vol. 344). John Wiley \& Sons.

Kleinberg, J., 2003. Bursty and hierarchical structure in streams. Data Mining and Knowledge Discovery, 7(4), 373-397.

Koutamanis, A., 2000. Digital architectural visualization. Automation in Construction, 9(4), 347-360.

Linderoth, H. C., 2010. Understanding adoption and use of BIM as the creation of actor networks. Automation in Construction, 19(1), 66-72.

Mahalingam, A., Yadav, A. K., \& Varaprasad, J., 2015. Investigating the Role of Lean Practices in Enabling BIM Adoption: Evidence from Two Indian Cases. Journal of Construction Engineering and Management, 141(7), 05015006.

Mok, K. Y., Shen, G. Q., \& Yang, J., 2015. Stakeholder management studies in mega construction projects: A review and future directions. International Journal of Project Management, 33(2), 446-457.

Murphy, M. E., 2014. Implementing innovation: a stakeholder competency-based approach for BIM. Construction Innovation, 14(4), 433-452.

Newman, M. E., 2006. Modularity and community structure in networks. Proceedings of the National Academy of Sciences, 103(23), 8577-8582.

Oakley, J., 2012. Getting a BIM rap: Why implementations fail, and what you can do about it. AECbytes Viewpoint.

Pollack, J., \& Adler, D., 2015. Emergent trends and passing fads in project management research: A scientometric analysis of changes in the field. International Journal of Project Management, 33(1), 236-248.

Redmond, A., Hore, A., Alshawi, M., \& West, R., 2012. Exploring how information exchanges can be enhanced through Cloud BIM. Automation in Construction, 24, 175-183.

Riaz, Z., Arslan, M., Kiani, A. K., \& Azhar, S., 2014. CoSMoS: A BIM and wireless sensor based integrated solution for worker safety in confined spaces. Automation in Construction, 45, 96-106.

Ronda-Pupo, G. A., \& Guerras-Martin, L. Á., 2012. Dynamics of the evolution of the strategy concept 1962 - 2008: a co - word analysis. Strategic Management Journal, 33(2), 162-188.

Sacks, R., Treckmann, M., \& Rozenfeld, O., 2009. Visualization of work flow to support lean 
construction. Journal of Construction Engineering and Management, 135(12), 1307-1315.

Sacks, R., Koskela, L., Dave, B. A., \& Owen, R., 2010. Interaction of lean and building information modeling in construction. Journal of construction engineering and management, 136(9), 968-980.

Samuelson, O., \& Björk, B. C., 2013. Adoption processes for EDM, EDI and BIM technologies in the construction industry. Journal of Civil Engineering and Management, 19(sup1), S172-S187.

Samuelson, O., \& Björk, B. C., 2014. A longitudinal study of the adoption of IT technology in the Swedish building sector. Automation in Construction, 37, 182-190.

Sebastian, R., 2011. Changing roles of the clients, architects and contractors through BIM. Engineering, Construction and Architectural Management, 18(2), 176-187.

Shanghai Tower, 2015. About Us. Retrieved 10 August, 2015, from http://www.shanghaitower.com.cn/enversion/show_news.asp?c_id=219.

Singh, V., \& Holmström, J., 2015. Needs and technology adoption: observation from BIM experience. Engineering, Construction and Architectural Management, 22(2), 128-150.

Son, H., Lee, S., \& Kim, C., 2015. What drives the adoption of building information modeling in design organizations? An empirical investigation of the antecedents affecting architects' behavioral intentions. Automation in Construction, 49, 92-99.

Succar, B., 2009. Building information modelling framework: A research and delivery foundation for industry stakeholders. Automation in construction, 18(3), 357-375.

Succar, B., \& Kassem, M., 2015. Macro-BIM adoption: Conceptual structures. Automation in Construction, 57, 64-79.

Thompson-Reuters, 2014. Web of Science. Retrieved 28 May, 2016, from http://homsonreuters.com/content/ dam/openweb/ documents/pdf/ scholarly-scientific-research/ fact-sheet/wos-next-gen-brochure.pdf.

Volk, R., Stengel, J., \& Schultmann, F., 2014. Building Information Modeling (BIM) for existing buildings_-Literature review and future needs. Automation in Construction, 38, 109-127.

Wang, J., Wang, X., Shou, W., \& Xu, B., 2014. Integrating BIM and augmented reality for interactive architectural visualisation. Construction Innovation, 14(4), 453-476.

Wang, X., Love, P. E., Kim, M. J., Park, C. S., Sing, C. P., \& Hou, L., 2013. A conceptual framework for integrating building information modeling with augmented reality. Automation in Construction, $34,37-44$.

Won, J., Lee, G., Dossick, C., \& Messner, J., 2013. Where to focus for successful adoption of building information modeling within organization. Journal of Construction Engineering and Management, 139(11), 04013014.

Wong, J. K. W., \& Zhou, J., 2015. Enhancing environmental sustainability over building life cycles through green BIM: A review. Automation in Construction, 57, 156-165.

Yalcinkaya, M., \& Singh, V., 2015. Patterns and trends in Building Information Modeling (BIM) research: A Latent Semantic Analysis. Automation in Construction, 59, 68-80. 
Table 1

Distribution of selected papers.

\begin{tabular}{|c|c|c|}
\hline Journal name & $\begin{array}{c}\text { Number of retrieved papers } \\
\text { from WoS and Scopus }\end{array}$ & $\begin{array}{l}\text { Number of selected } \\
\text { papers for this study }\end{array}$ \\
\hline Automation in Construction & 152 & 30 \\
\hline $\begin{array}{c}\text { Journal of Construction Engineering and } \\
\text { Management }\end{array}$ & 27 & 18 \\
\hline Construction Innovation & 22 & 15 \\
\hline $\begin{array}{c}\text { Journal of Professional Issues in Engineering } \\
\text { Education and Practice }\end{array}$ & 13 & 11 \\
\hline Journal of Information Technology in & 28 & 11 \\
\hline Journal of Management in Engineering & 12 & 9 \\
\hline Construction Management and Economics & 10 & 7 \\
\hline $\begin{array}{c}\text { Engineering, Construction and Architectural } \\
\text { Management }\end{array}$ & 6 & 6 \\
\hline Building and Environment & 4 & 3 \\
\hline Building Research and Information & 4 & 3 \\
\hline International Journal of Project Management & 4 & 3 \\
\hline $\begin{array}{l}\text { Proceedings of the Institution of Civil } \\
\text { Engineers-Civil Engineering }\end{array}$ & 4 & 3 \\
\hline Canadian Journal of Civil Engineering & 5 & 2 \\
\hline KSCE Journal of Civil Engineering & 8 & 2 \\
\hline Project Management Journal & 2 & 2 \\
\hline Journal of Civil Engineering and Management & 7 & 1 \\
\hline Total & 308 & 126 \\
\hline
\end{tabular}


Table 2

Normalized keywords list.

\begin{tabular}{ccc}
\hline No. & Primary keywords & Normalized keywords \\
\hline 1 & Application areas & Application area \\
2 & Case studies & Case study \\
3 & Costs & Cost \\
4 & Construction projects & Construction project \\
5 & Construction sites & Construction site \\
6 & Computer-aided design (cad) & Computer aided design \\
7 & Computer-aided design & Computer aided design \\
8 & Curricula & Curriculum \\
9 & Decision-making & Decision making \\
10 & Engineering and construction (aec) industry & Construction industry \\
11 & Facilities management & Facility management \\
12 & Information technologies & Information technology \\
13 & Information technology (it) & Information technology \\
14 & Quantity takeoff & Quantity take-off \\
15 & Surveys & Survey \\
16 & Structural equation modeling (sem) & Structural equation model \\
17 & Technology acceptance model (tam) & Technology acceptance model \\
18 & Tam (technology acceptance model) & Technology acceptance model \\
19 & Three-dimensional (3d) models & Three-dimensional models \\
20 & 3d models & Three-dimensional models \\
\hline
\end{tabular}


Table 3

Whole characteristics of the keyword co-occurrence network.

\begin{tabular}{cccccc}
\hline Network & Nodes & Edges & Density & Modularity Q & Mean Silhouette \\
\hline $\begin{array}{c}\text { keyword } \\
\text { co-occurrence }\end{array}$ & 490 & 1448 & 0.0121 & 0.8115 & 0.9372 \\
\hline
\end{tabular}

Table 4

Eight research clusters in the field of MA-BIM.

\begin{tabular}{|c|c|c|c|}
\hline Cluster & Size & Silhouette & Top terms \\
\hline$\# 0$ & 15 & 0.723 & Collaboration, Collaborative design, Interoperability \\
\hline$\# 1$ & 14 & 0.845 & $\begin{array}{l}\text { Innovation, Innovation processes, Innovation diffusion, } \\
\text { Innovation-related decisions }\end{array}$ \\
\hline$\# 2$ & 11 & 0.892 & Stakeholder management, Stakeholder competence, Actor network \\
\hline$\# 3$ & 11 & 0.909 & Visualization, Visualized management, Real-time visualization \\
\hline$\# 4$ & 9 & 0.948 & Adoption, Industry adoption, Behavioral intentions, Point of adoption \\
\hline$\# 5$ & 9 & 0.912 & Cultural transmission, Policy transmission, BIM diffusion policy \\
\hline \#6 & 5 & 1 & Framework, Conceptual framework, Theoretical framework \\
\hline$\# 7$ & 5 & 0.947 & O\&M, Existing building, Refurbishment, Deconstruction \\
\hline
\end{tabular}




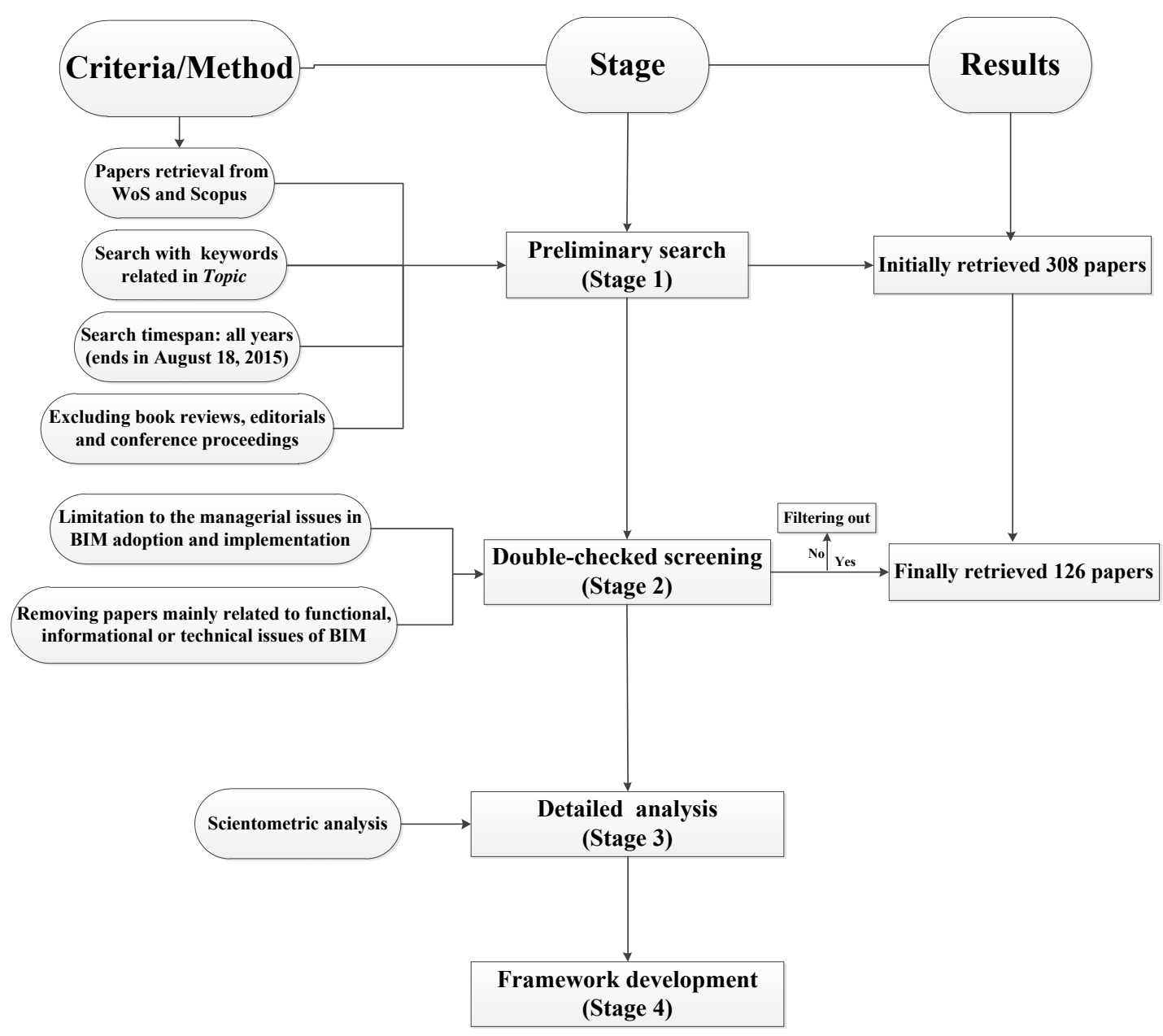

Fig. 1. Research framework of this study.

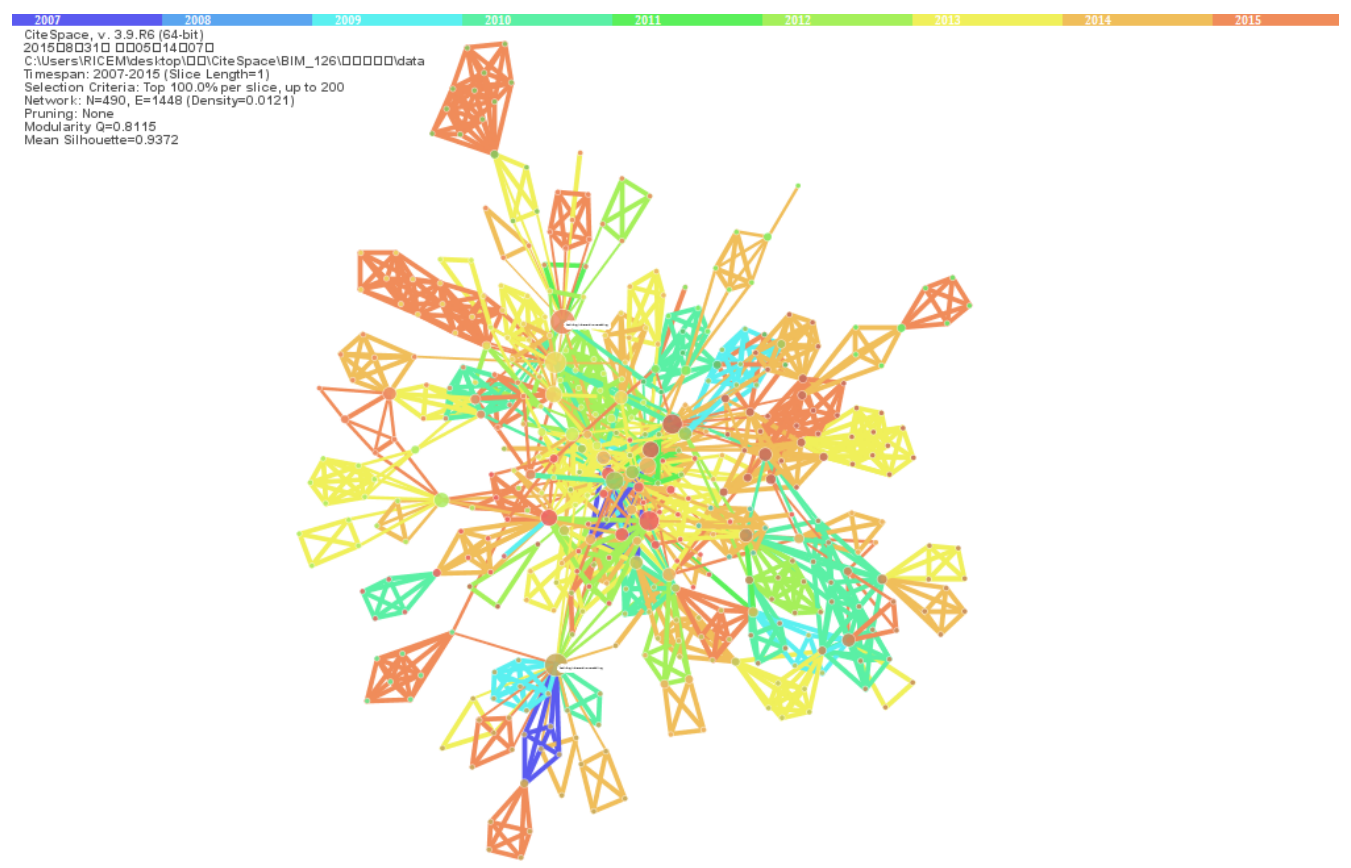

Fig. 2. Keyword co-occurrence network: 2007-2015. 


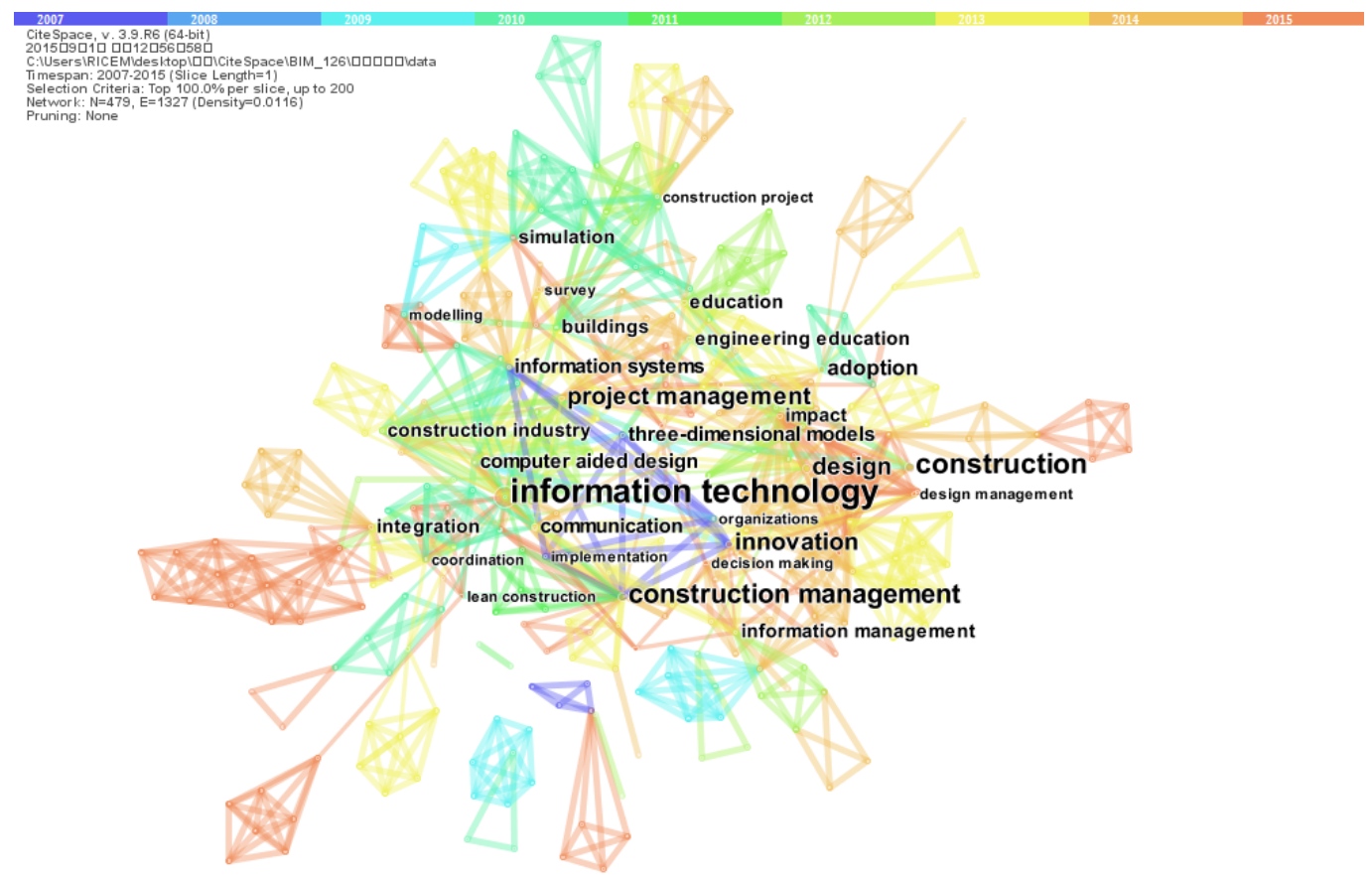

Fig. 3. Top keywords occurring more than twice: 2007-2015.

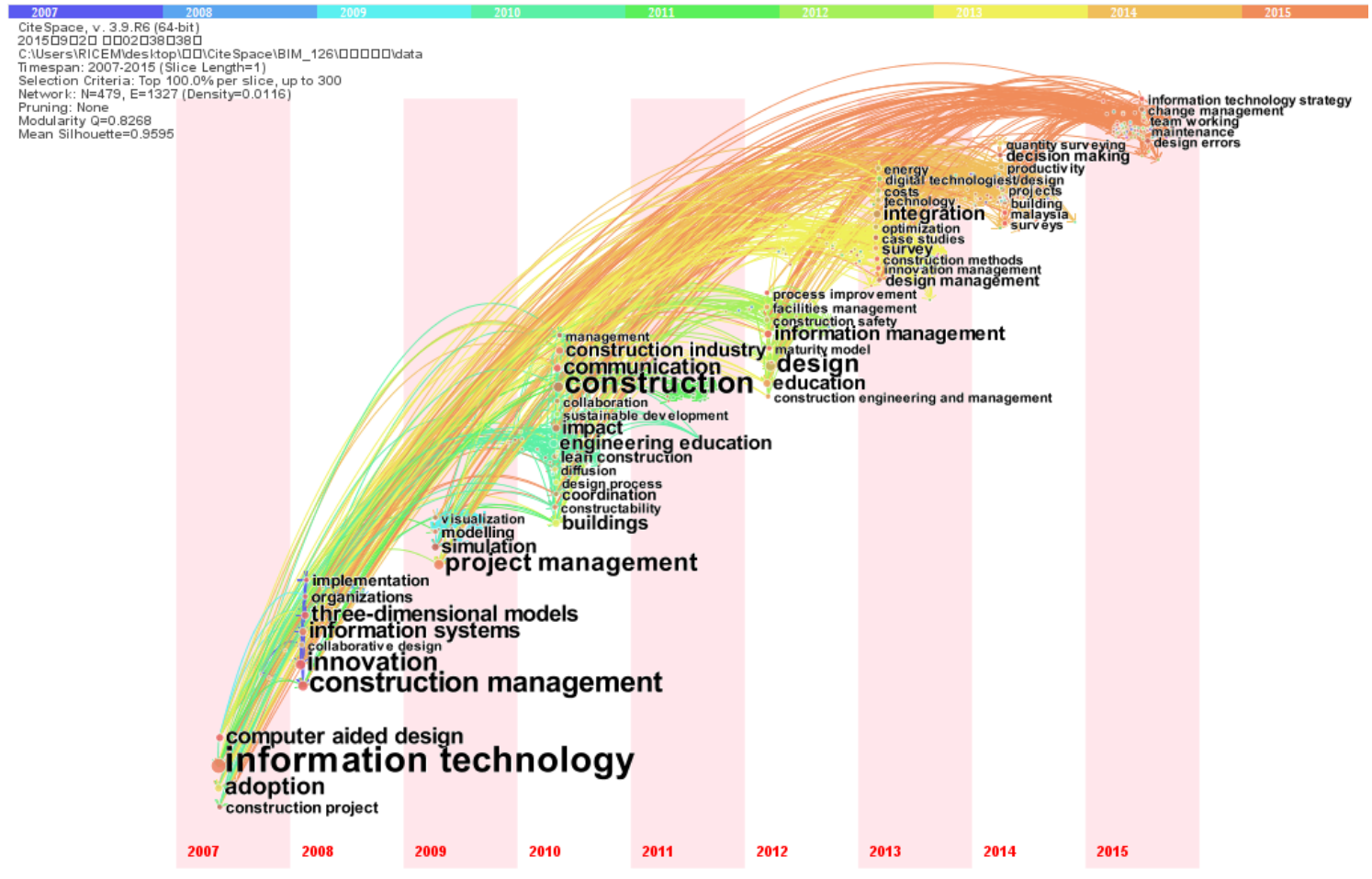

Fig. 4. A timeline view of keyword co-occurrence network: 2007-2015. 


\begin{tabular}{|c|c|c|c|c|c|}
\hline Keywords & Year & Strength & Begin & End & $2007-2015$ \\
\hline three-dimensional models & 2007 & 1.1287 & 2007 & 2010 & \\
\hline change management & 2007 & 0.9851 & 2007 & 2015 & 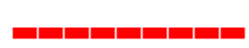 \\
\hline information technology strategy & 2007 & 0.9851 & 2007 & 2015 & שصسصسשصسص \\
\hline maintenance & 2007 & 0.9851 & 2007 & 2015 & تصسصت \\
\hline design errors & 2007 & 0.9851 & 2007 & 2015 & صسمسصسصسمس \\
\hline team working & 2007 & 0.9851 & 2007 & 2015 & صستسمستسمس \\
\hline decision making & 2007 & 0.9686 & 2007 & 2013 & 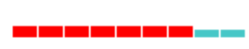 \\
\hline design & 2007 & 0.9065 & 2007 & 2011 & \\
\hline construction & 2007 & 0.7398 & 2007 & 2012 & 드늠 \\
\hline collaborative design & 2007 & 0.9645 & 2008 & 2015 & تسعستس \\
\hline project management & 2007 & 0.2976 & 2009 & 2013 & $=-$ \\
\hline innovation & 2007 & 1.1533 & 2010 & 2012 & - \\
\hline organizations & 2007 & 0.6091 & 2010 & 2015 & שص \\
\hline collaboration & 2007 & 0.4853 & 2010 & 2013 & 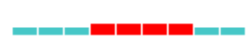 \\
\hline management & 2007 & 0.4853 & 2010 & 2013 & $=-10$ \\
\hline construction industry & 2007 & 0.4746 & 2010 & 2012 & 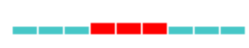 \\
\hline lean construction & 2007 & 1.1636 & 2011 & 2015 & سصسصس \\
\hline impact & 2007 & 0.8715 & 2011 & 2013 & 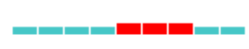 \\
\hline diffusion & 2007 & 0.7749 & 2011 & 2015 & سمستسمستس \\
\hline constructability & 2007 & 0.7749 & 2011 & 2015 & \\
\hline sustainable development & 2007 & 0.7749 & 2011 & 2015 & 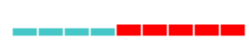 \\
\hline information systems & 2007 & 0.6545 & 2011 & 2015 & 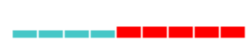 \\
\hline adoption & 2007 & 0.3972 & 2011 & 2013 & 므- \\
\hline modelling & 2007 & 1.0924 & 2012 & 2015 & 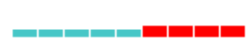 \\
\hline education & 2007 & 0.5654 & 2012 & 2015 & 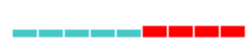 \\
\hline
\end{tabular}

Fig. 5. Top 25 bursting keywords: 2007-2015 (sort by the beginning year of burst).

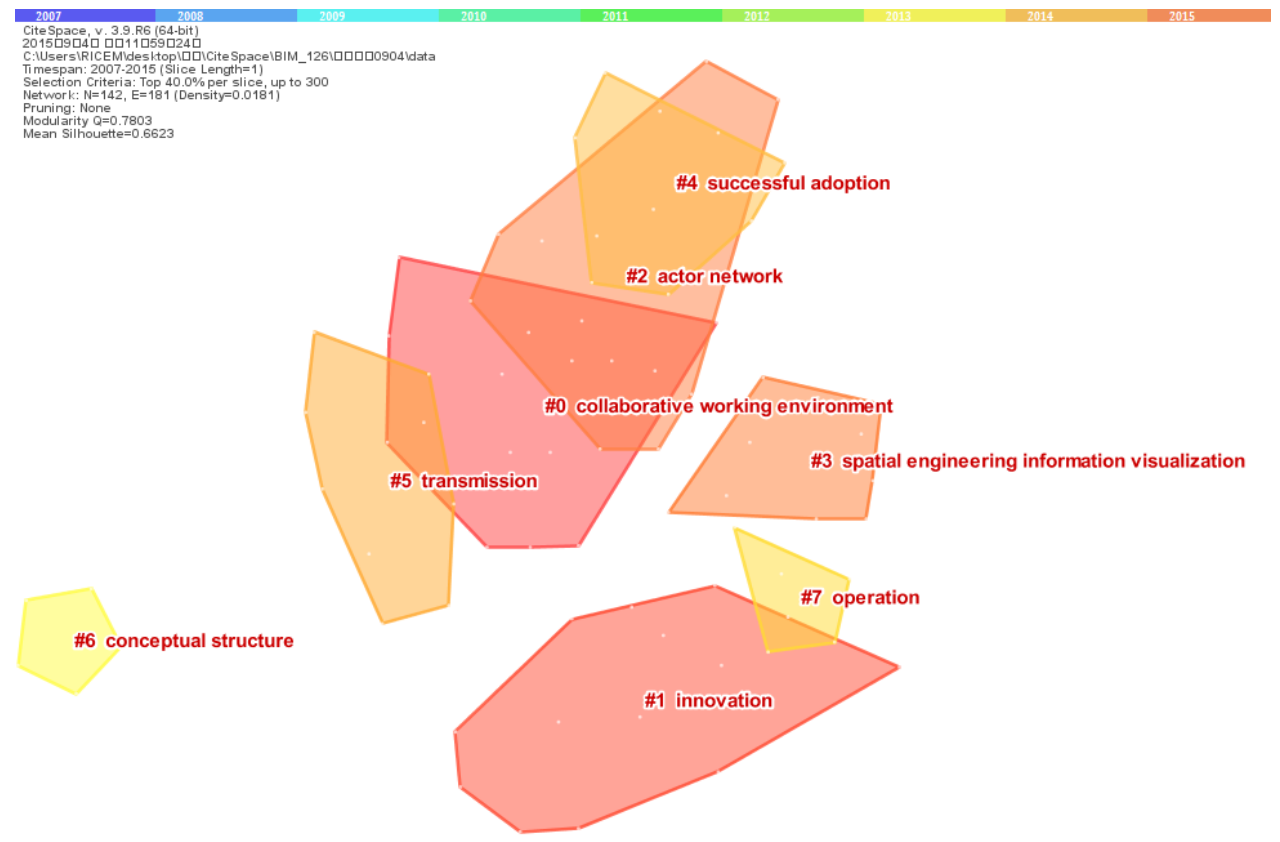

Fig. 6. Cluster analysis in MA-BIM field: 2007-2015. 


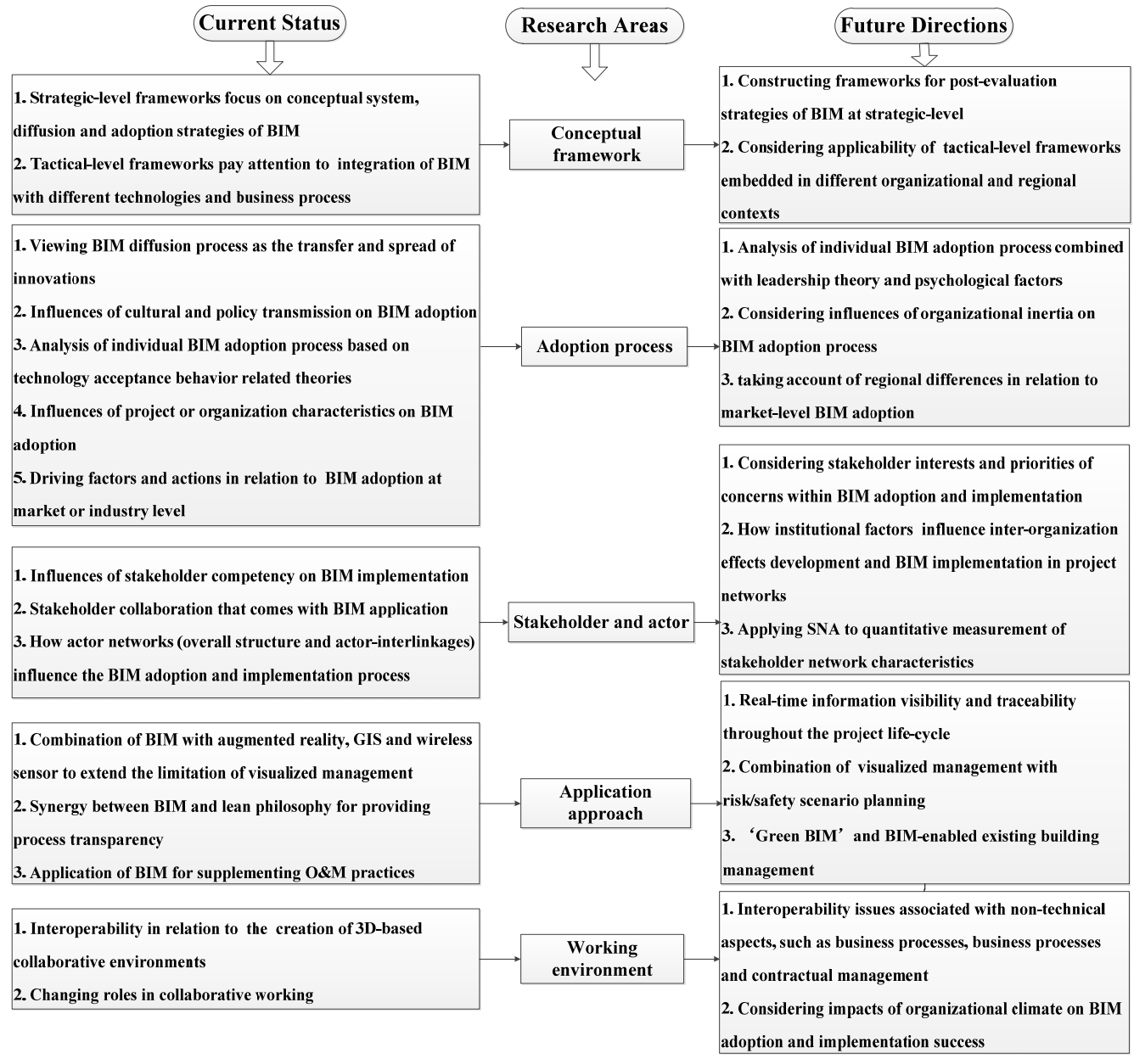

Fig. 7. The conceptual framework for MA-BIM.

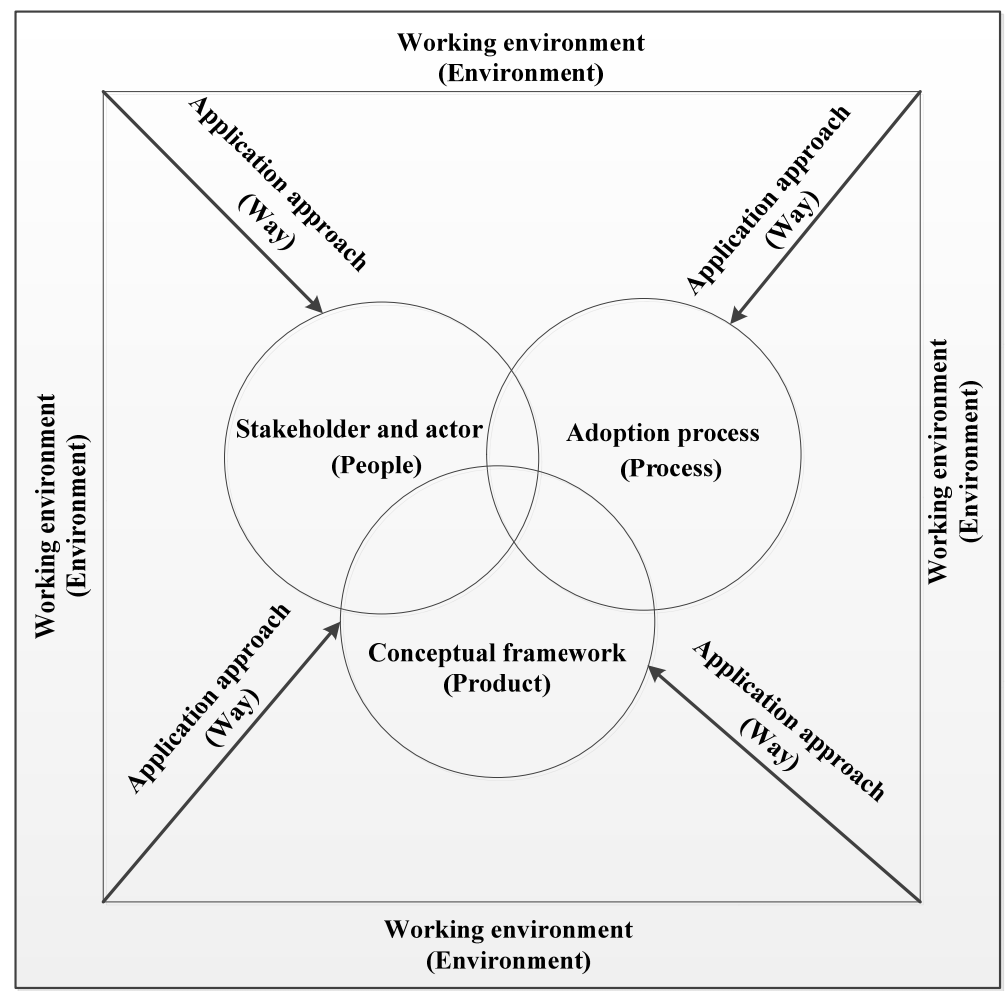

Fig. 8. The five principal research areas of MA-BIM 